Review

\title{
Education, Work, and Motherhood in Low and Middle Income Countries: A Review of Equality Challenges and Opportunities for Women with Disabilities
}

\author{
Belaynesh Tefera ${ }^{1,2, *}$, Marloes L. van Engen ${ }^{1}$, Alice Schippers ${ }^{3,4}$, Arne H. Eide ${ }^{5,6}$, Amber Kersten ${ }^{1}$ and Jac van \\ der Klink ${ }^{1,7}$ \\ ${ }^{1}$ Department of Human Resource Studies, Tilburg University, 5037 AB Tilburg, The Netherlands; \\ E-Mails: b.teferanidaw@uvt.nl (B.T.), m.I.vengen@tilburguniversity.edu (M.v.E.), a.kersten@tilburguniversity.edu (A.K.), \\ j.I.vdrklink@uvt.nl (J.v.d.K.) \\ 2 School of Commerce, College of Business and Economics, Addis Ababa University, Addis Ababa, Ethiopia; \\ E-Mail: belaynesh.tefera@aau.edu.et \\ ${ }^{3}$ Disability Studies Netherlands, 3811 HR Amersfoort, The Netherlands; E-Mail: alice.schippers@disabilitystudies.nl \\ ${ }^{4}$ Department of Medical Humanities, VU University Medical Centre, 1081 HV Amsterdam, The Netherlands \\ ${ }^{5}$ SINTEF Technology and Society, PB 124, 0314 Oslo, Norway; E-Mail: arne.h.eide@sintef.no \\ ${ }^{6}$ Centre for Rehabilitation Studies, Stellenbosch University, P.O. Box 241, Cape Town, South Africa \\ 7 Scientific Center for Care and Welfare, Tilburg University, 5037 AB Tilburg, The Netherlands \\ * Corresponding author
}

Submitted: 1 October 2017 | Accepted: 14 February 2018 | Published: 26 March 2018

\begin{abstract}
This study looks at the equality challenges and opportunities for women with disabilities in low and middle income countries (LMICS) to participate and succeed in education, employment and motherhood. It is based on a systematic review of the literature from academic and non-governmental organization databases. The search of these databases yielded 24 articles, which were subsequently passed through open, axial, and selective coding. The resulting review found that women with disabilities in LMICs have severe difficulty participating and succeeding in education, employment and motherhood due to a number of interrelated factors: (i) hampered access to education, employment, intimacy and marriage, (ii) stigma and cultural practices resulting in discrimination and prejudice, and (iii) lack of support from family, teachers and institutions-all of which are exacerbated by poverty. Support from families, communities, the government, and nongovernmental organizations improves women's ability to fulfil their social roles (as students, employees and mothers), resulting in a better quality of life. Strategies that create awareness, minimize poverty and facilitate justice may improve the opportunities for women with disabilities in LMICs to participate in education, employment and motherhood, as well as their ability to succeed in these domains.
\end{abstract}

\section{Keywords}

capability; disability; education; employment; low and middle income countries; motherhood; social roles; women with disabilities

\section{Issue}

This review is part of the issue "Disability Equality: In Theory and Practice", edited by Mark Priestley (University of Leeds, UK) and Lisa Waddington (Maastricht University, The Netherlands).

(c) 2018 by the authors; licensee Cogitatio (Lisbon, Portugal). This article is licensed under a Creative Commons Attribution 4.0 International License (CC BY). 


\section{Introduction}

Participation in social roles that are valued by society can lead to many benefits for those who have the opportunity to take on these roles (Osburn, 2006). Among other things, these benefits may include: a sense of belonging, an education, the development and exercise of one's capabilities, opportunities to participate in society, a decent material standard of living, and opportunities for work and self-support (Osburn, 2006; Wolfensberger, Thomas, \& Caruso, 1996). The purpose of the United Nations Convention on the Rights of Persons with Disabilities (CRPD) is to promote, protect and ensure the full and equal enjoyment of all human rights and fundamental freedoms by all persons with disabilities (Article 1), and it sets out a number of rights of persons with disabilities, including the right to education and employment on an equal basis to others, as well as certain rights related to family and reproduction (United Nations, 2006). The Convention recognises that "disability results from the interaction between persons with impairments and attitudinal and environmental barriers that hinders their full and effective participation in society on an equal basis with others" (Preamble, para. e, United Nations, 2006). It requires states parties to be aware that persons with disabilities enjoy legal capacity on an equal basis with others and should be supported to exercise their legal capacity (Article 12, United Nations, 2006). The Convention makes the participation of persons with disabilities one of its principles and enshrines the right of disabled persons to participate fully and equally in the community, in education, and in all aspects of life. According to the World Disability Report (WHO \& World Bank, 2011), participation in social roles by people with disabilities is much more limited than participation by the general population; this is particularly true for women with disabilities, who suffer double discrimination on account of disability and gender. The 2030 Sustainable Development Agenda (6), which is captured in the Sustainable Development Goals (SDGs; United Nations, n.d.) (7), states that addressing the needs of, and barriers faced by, people in disadvantaged groups is a prerequisite for an inclusive and equitable society. This is reflected in the pledge 'leave no one behind'.

Understanding the opportunities and challenges that women with disabilities in low and middle income countries (LMICS) face in participating meaningfully in education, employment and family life (Tefera \& Van Engen, 2016; Tefera, Van Engen, Van der Klink, \& Schippers, 2017 ) is critical, not only to the articulation of inclusive development theories, but also to the design of appropriate (family) interventions to improve quality of life. While there has been increased interest in disability issues in developing countries, there is limited data available in this field (Loeb \& Eide, 2008). The existing data is often fragmented and anecdotal (Groce, Kett, Lang, \& Trani, 2011). The small, but growing, literature base indicates that the substantial links between education, em- ployment and family life are more multifaceted and interrelated than previously assumed. The intersectionality of high levels of poverty with gender and disability in LMICs makes disability equality substantially different in these countries than in high income countries, which are also typically better researched. Our review, therefore, focused specifically on disability equality in LMICs.

To critically analyse all present and published knowledge, we systematically reviewed the literature on LMICs that looks at the relationship between education, employment and motherhood as providing access to the major social roles of student, employee and mother in order to answer the following research question:

What are the important challenges and opportunities for women with disabilities in low and middle income countries to participate in education, employment and motherhood, and what factors determine their participation in the important social roles emerging from these (of student, employee and mother), as well as their achievement of valuable goals in life?

In the following paragraphs we introduce the concept of 'social role valorization' (SRV; Osburn, 2006; Wolfensberger, 1983; Wolfensberger \& Thomas, 2005) and the capability approach (Nussbaum, 2006; Robeyns, 2005; Sen, 1983, 2009), which will be used as a guiding framework to understand disability inequality in participation in social roles and the achievement of valuable goals in life. Subsequently, we present the literature review, with a focus on the roles that women with disabilities have as students, employees and mothers. In the discussion of this review, we will argue that these roles are interrelated, as achievements in one impact on opportunities in the others.

\section{Theoretical Framework}

The social roles that individuals identify with and that others in society attribute to them vary. The concept of shaping social roles by means of enhancement of competencies and image is referred to as SRV, a term coined by Wolfensberger (1983). Women with disabilities can identify as students, employees, mothers and so forth. These roles are valued in society-but not all people are valued by society. People with disabilities are often societally devalued, or at high risk of becoming devalued (Osburn, 2006). For example, society does not identify women with disabilities as capable of playing a valuable role as students, employees or mothers. Adopting valued social roles allows women with disabilities to engage in meaningful activities, which promotes self-esteem and confidence, which, in turn, helps them to improve their quality of life (Osburn, 2006; Flynn \& Aubury, 1999; Gardner \& Carran, 2005; Lemay, 2006). Ultimately, participation in valued social roles can lead to the adoption of other valued social roles. For example, a woman with a disability who is educated and employed may be confi- 
dent enough to strive for additional socially-valued roles, such as marriage and motherhood.

As stigma is imposed on women with disabilities, and cannot be 'disposed' of, women often tend to internalize and accept society's negative evaluation. Being stigmatized results in rejection, exclusion and discrimination, thus limiting the opportunities for women with disabilities to achieve their potential and increasing the likelihood of poor treatment by others in society. Wolfensberger and Thomas (1994) emphasize that if people are devalued by society, or are at risk of being devalued, their acquisition of valued social roles may decrease the stigma and discrimination they experience.

Another framework that can help us to understand the disability inequality of women in LMICs is the capability approach. This approach, introduced by Sen (1980, $1993,2009)$, is a normative approach that states that individuals should have the capabilities to conceive, pursue, and revise their life plans (Alkire, 2002, 2005; Nussbaum, 2006; Robeyns, 2005; Sen, 1999; Venkatapuram, 2011). Society or societal institutions should enable people to achieve these capabilities. There are three important elements in the capability approach, namely: capabilities, functionings and freedom. In the most basic sense, functionings represent the states and activities that constitute a person's being: "beings and doings people have reason to value" (Sen, 1992, p. 40). The capabilities of an individual reflect the different combinations of functionings that a person is able to achieve, depending on his or her particular circumstances-in other words, the various combinations of what $s /$ he can do or be. According to Sen, an individual's well-being should be assessed in terms of capabilities (potentials to achieve), as functionings (achievements) may be the result of constrained choices or reflect a limitation in choices.

So, it is important to evaluate what an individual can do, or is able (and enabled) to do, and not just what they actually do. Capabilities represent a person's opportunity and ability to achieve valuable outcomes, taking into account relevant personal characteristics and external factors: being able and enabled.

In the capability approach it is recognized that all people are different in terms of their resources and characteristics. Because people differ in terms of these 'inputs', people also need different means or 'conversion factors' to achieve equity in opportunities and outcomes. Therefore, in the capability approach, justice is not considered to be equality in means (everybody has the right to the same means), but equality in outcomes (everybody should have the same opportunity to achieve valuable outcomes). Hence, equality for women with disabilities is about having the opportunity and ability to shape one's life in terms of one's valued goals in relation to education, employment and motherhood, which might require extra means for this group. This emphasis on equality in outcomes is in accordance with the above mentioned requirement of the CRPD (Article 12, United Nations, 2006).

\section{Method}

The review methodology by Hannula, Kaunoen and Tarkka (2007, p. 105) was followed for the literature review. By exploring and evaluating findings of previous published research, a review constitutes an essential aspect of all research related to the themes, enabling the work to be set in the context of what is known and what is not known (Saunders \& Rojon, 2011). Grounded theory, as a method of rigorously reviewing literature, was used during the analysis stage (Wolfswinkel, Furtmueller, \& Wilderom, 2013). This method involves five steps: define, search, select, analyse, and present. Several databases were used to identify suitable articles: Web of Science, PsychINFO, Google Scholar, and MEDLINE. The keywords and combination of keywords used to search all databases included: "(disabled women or women with disabilities) OR (low or middle income countries or Global South), OR education OR employment OR (motherhood or intimacy or marriage) OR family life". The criteria for the inclusion of articles were: (i) published in English, (ii) full article accessible, and (iii) peer reviewed and published during the period 2006-2015. Articles were excluded when: (i) there was no reference to women with disabilities, (ii) developing or low or middle income countries were not addressed, and (iii) there was no reference to either of the three themes (education, employment, or motherhood) and no reference to the terms disabled, disabling, disability or disabilities. A total of 25,566 articles were initially identified and included in the search.

The selection process is outlined indicated in Chart 1 , which shows the coding process from the database selection up to the final coding round and the final selection of articles to analyse.

\section{Coding}

The analysis stage passed through open, axial and selective coding. In the open coding, all statements about education, employment and motherhood were selected. During the axial coding, concepts were categorized based on the three themes (education, employment, motherhood). Repeated ideas (different authors using similar terms to explain the same idea of discrimination in relation to the themes) were included if they were expressed in different ways. Two coders (first and fourth author) independently selected key fragments from the articles on the themes of education, employment and motherhood, producing a table that also included some of the study characteristics of the articles (e.g., sample information, methodology). The two tables were compared by the second and third author and a final table created, which was subsequently used for the analyses (available from the authors upon request). 


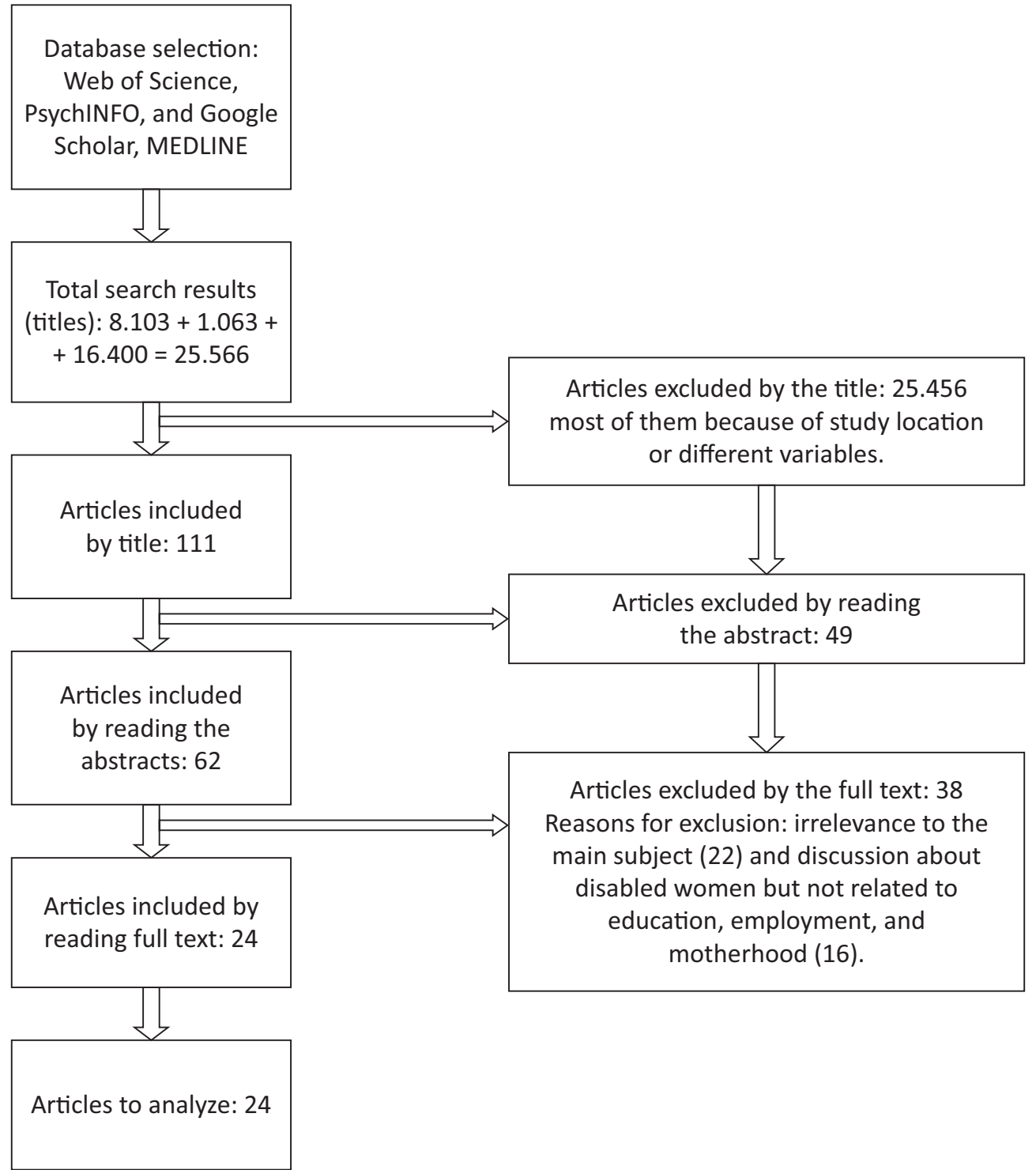

Chart 1. Study selection process.

\section{Description of Sample}

The 24 articles follow different methodologies. There were: 11 qualitative studies (Braathen \& Kvam, 2008; Dark and Light Blind Care, 2008; Dhungana, 2007; Kassah, Kassah, \& Agbota, 2013; Kiani, 2009; Kvam \& Braathen, 2008; Lamichhane, 2012a; Mitra, Posarac, \& Vick, 2011; Morrison et al., 2014; Naami, Hayashi, \& Liese, 2012; Simkhada et al., 2013; Tuomi, Lehtomäki, \& Matonya, 2015), 7 reviews (Emmett \& Alant, 2006; Groce et al., 2011; Moodley \& Graham, 2015; Opini, 2010; Ortoleva, 2010; Parnes et al., 2009), 1 quantitative study (Naami, 2015), 2 mixed studies (qualitative and quantitative) (Lamichhane, 2012b; Salome, Mbugua, \& Ong'eta, 2013), 1 examination of UN disability convention proceedings (UN \& UNC, 2012), 1 examination of domestic legislation (Gupta, 2013), and 1 conference paper (which is on the right to autonomy and self-determination) (Frohmader \& Ortoleva, 2013).

\section{Results}

This section presents the results of the literature review in terms of how access to education, employment, intimacy and marriage; stigma related to cultural values and cultural practices; and support (or the lack thereof) influences the participation of disabled women in education, employment, and motherhood and family life.

\subsection{Education}

In the literature reviewed, there are 16 articles that mention the education issues of women with disabilities in LMICs. In a study using the World Health Survey data, Mitra et al. (2011) compared 15 developing countries in Sub-Saharan Africa, Asia and Latin America in terms of the prevalence of disability and differences between individuals with and without disabilities for several indicators of poverty, including the proportion of primary 
school completion. In all countries, except Burkina Faso (where lack of primary school education is low in general, less than $89 \%$ ), the proportion of primary school completion rates is lower among persons with disabilities. In Mauritius and Zimbabwe, primary school completion for persons with disabilities is about the same as for persons without disabilities. In other countries, such as Ghana, Kenya, Malawi, Zambia, Bangladesh, Lao PDR, Pakistan, Philippines, Brazil, Dominican Republic, Mexico and Paraguay, the difference in primary school completion rates between persons with and without disabilities is somewhat smaller. Mitra et al. (2011) conclude that, in terms of poverty (using a multidimensional indicator of poverty including education), women generally fare worse than men. Unfortunately, there are no analyses comparing poverty among men and women with and without disabilities.

In a study using different sources of panel data, Moodley and Graham (2015) compared the education level of men and women with and without disabilities in South Africa. They found that the higher you go in terms of education level, the lower the completion rate of women and men with disabilities. Although primary school completion among men and women with disabilities is higher (26.1\% and $28.6 \%$, respectively) than among men and women without disabilities $(21.4 \%$ and $20.0 \%$, respectively), the reverse pattern is found with higher levels of education: $32.7 \%$ of men and $30.8 \%$ of women with disabilities have 'some secondary education', compared to $50.6 \%$ of men and $48.4 \%$ of women without disabilities. The proportion of individuals with completed secondary level education is smallest for women with disabilities (9.2\%), compared to disabled men (12.8\%), non-disabled women (16.6\%), and nondisabled men (16.5\%). Tertiary education attainment is low: $1.6 \%$ for non-disabled men and women, compared to $0.7 \%$ for men and women with disabilities. In a large survey among men and women with disabilities (in which $42.1 \%$ of the respondents were women with disabilities) conducted in the Kathmandu valley of Nepal, Lamichhane $(2012 a, 2012 b)$ found the average years of schooling for persons with disabilities to be 8.8 years, compared to the country average of 9.4 years. However, those with hearing impairments ( 6.9 years) had much less schooling than those with visual ( 9 years) or physical impairments (10.9 years).

\subsubsection{Accessibility}

Reports that review different databases (Mitra et al., 2011; Opini, 2010; Parnes et al., 2009; UN General Assembly, 2012) conclude that women with disabilities face more difficulties than men with disabilities, or people without disabilities, in gaining access to education. For many of those who do access education, the continuation of education is also an issue. A study by Kassah et al. (2013), which interviewed five women with physical disabilities in Ghana who had faced physical abuse, found that the women did not complete school because of inability to pay school fees. Braathen and Kvam (2008) also found lack of money to be a main reason for quitting school early, while Kiani (2009), in explaining the perceived inability of women with disabilities in Cameroon, noted that some families prioritize their non-disabled daughters when paying school fees, as they believe educating women with disabilities is a waste of money. Other reasons for discontinuing education mentioned in the articles were: physical inaccessibility of schools (Braathen \& Kvam, 2008, Kiani, 2009), inadequate training of school teachers (Simkhada et al., 2013), and lack of encouragement from teachers (Tuomi et al., 2015).

\subsubsection{Stigma Related to Cultural Values and Practices}

A number of articles cite societal expectations that women with disabilities are either unable or unworthy of education as a major reason for lack of education opportunities. Kvam and Braathen in their study of the daily lives of 23 women with disabilities in Malawi (2008a) and follow-up study by Braathen and Kvam, using focus groups and interviews (2008b), as well as Lamichhane (2012a), who studied the employment situation of 402 persons with disabilities in Nepal, describe how the societal expectation that women with disabilities do not need education or special schools hinders women with disabilities from participating in education. Simkhada et al. (2013), in their qualitative exploratory study of knowledge and attitudes towards women with disabilities in rural Nepal, found that women with disabilities in LIMCs suffer from limited availability of resources for education (e.g., Braille facilities), because resources are channelled to non-disabled students, as women with disabilities are considered incapable of participating in education. Salome et al. (2013) report that low expectations by teachers and peers undermine female students' self-esteem. Female students are also teased and taunted by their peers and teachers and reported told that they are incapable of achieving high grades. Moreover, they also report that many women with disabilities experience gender based violence while undergoing education (Salome et al., 2013).

\subsubsection{Support and Lack of Support}

Four of the articles reviewed indicate family resistance to the education of women with disabilities (Dhungana, 2007; Kiani, 2009; Lamichhane, 2012a; Kassah et al., 2013). Some families not only deny girls with disabilities access to school, but hide them away due to fear of stigma (Gupta, 2013; Lamichhane, 2012a). Kassah et al. (2013) explain the lack of support from parents and other family members as reluctance to support their daughters with disabilities. Respondents in that study indicated that families prioritize the education needs of their nondisabled children, because they believe that educating children with disabilities is a waste of resources. 
Yet, paradoxically, some articles mention that educating women with disabilities promotes their acceptance by their family and society. For example, Tuomi et al. (2015) note that educated women with disabilities gain value and respect within their family and are allowed to take part in family discussions and decision-making. Braathen and Kvam (2008a) found that educating women with disabilities makes them more confident.

Several articles also stress the importance of support within the education system. Emmett and Alant (2006), for instance, conclude this from a pilot study that interviewed Tanzanian women with disabilities in higher education. Tuomi et al. (2015) found clear indications that services, such as guidance and counselling, contribute to the success of women with disabilities who have started education. The authors acknowledge that the extra help received by disabled women contributes significantly to their success; for example, some teachers give women with disabilities preferential seating, which enables these students to become known to their teachers.

\subsection{Employment}

There are 14 articles that discuss the participation of women with disabilities in LMICs in employment. In some articles the participation of women with disabilities is compared to the participation of either men with disabilities or women without disabilities. On a global scale, the employment rate of men without disabilities is $85 \%$, compared to $75 \%$ for women without disabilities; for men with disabilities, the employment rate is $52 \%$, compared to $48 \%$ for women with disabilities (Salome et al., 2013). In LMICs, much larger differences are reported between men and women with disabilities: almost $60 \%$ of women with disabilities in Ghana are unemployed, compared to $40 \%$ of men with disabilities (Naami, 2015).

Employment has three important aspects: obtaining employment, job retention, and employment conditions. For all three aspects, more problems are experienced by women with disabilities in LMICs as discussed in the following sub-sections.

\subsubsection{Obtaining and Retaining Employment}

Nine studies mention obtaining employment (Dark and Light Blind Care, 2008; Gupta, 2013; Kiani, 2009; Lamichhane, 2012b; Moodley \& Graham, 2015; Naami, 2015; OHCHR, 2012; Ortoleva, 2010; Opini, 2010) and one study mentions retaining a job as problems for women with disabilities (OHCHR, 2012). Furthermore, even when women with disabilities in LMICs have obtained and retained a job, they have difficulties with employment conditions. Lower than average wages are reported for employed women with disabilities in three studies (OHCHR, 2012; Naami, 2015; Ortoleva, 2010). Little career progression for women with disabilities is reported in two studies (Naami, 2015; OHCHR, 2012) and less interesting jobs for women with disabilities is mentioned in two studies (Naami, 2015; Ortoleva, 2010). Underemployment, related to lower wages, but also to less challenging jobs, for women with disabilities is referred to in one study (Groce et al., 2011).

\subsubsection{Employment Conditions}

Several studies mention the relationship between employment conditions and other aspects of the lives of women with disabilities in LMICs. Although in most studies the design did not allow for conclusions to be drawn on causal relationships, eight studies make suggestions about the causes of the poor employment status of these women. Cultural stigma-referred to 'stereotyping', 'discrimination' or 'traditional attitudes' - is mentioned in five studies (Dark and Light Blind Care, 2008; Gupta, 2013; Kiani, 2009; Lamichhane, 2012b; Naami, 2015). Related to this, Moodley and Graham (2015) report that, in South Africa, black women with disabilities experience discrimination based on the intersection between disability, gender, race and poverty. Moodley and Graham (2015) further explain that women with disabilities experience stigma simultaneously because of disability and (related) unemployment.

Lack of education and vocational skills of women with disabilities is named in three studies (Dhungana, 2007; Naami, 2015; Opini, 2010). Opini states that there is a mismatch between the vocational skills that women with disabilities are trained in and the needs of the job market. In a review on the participation of persons with disabilities in the labour force, Opini (2010) reported that women with disabilities are further disadvantaged because of their gender. In two studies, the consequences of being unemployed are identified. Naami (2015) states that the limited participation of women with disabilities in the labour force results in their limited power and influence in decision-making, both at home and in the community. Moodley and Graham (2015, p. 31) describe the constraints women with disabilities face in terms of their gender, particularly with regard to labour market participation and income.

\subsection{Motherhood and Family Life}

There are 12 articles that discuss the experiences with motherhood and family life among women with disabilities in LMICs. Braathen and Kvam (2008) underline the needs of women with disabilities in terms of having children and establishing a family. However, women with disabilities are not expected to have relationships and are generally perceived as 'asexual'. Due to such perceptions, they have been denied the roles associated with womanhood, including the role of being a mother (Gupta, 2013). Furthermore, men prefer not to marry women with disabilities, because they are considered incapable of looking after their family. Additionally, there are myths that the presence of women with disabilities can bring bad luck to the family (Dhungana, 2007). 
Married life is more difficult to obtain for women with disabilities in LMICs such as Malawi and Ghana, as such women are perceived to be unable to perform the duties of a good wife and mother, according to societal expectations, and, therefore, may not be seen as suitable wives (Braathen \& Kvam, 2008; Price, 2011). Kassah et al. (2013) also confirm that women with disabilities are not considered to be capable of living up to female role expectations in terms of housekeeping, parenting, and motherhood. The practice of excluding women with disabilities from intimacy and married life results from the perception that they are either passive receivers of help or patients, or unable to fulfil the duties of marriage or give birth, as mentioned by Morrison et al. (2014) in a qualitative study about women's with disabilities in rural Nepal.

Other authors also report that women with disabilities in LMICs have a low likelihood of becoming intimate and married (Emmet \& Alant, 2006; Braathen \& Kvam, 2008; Parnes et al., 2009; Morrison et al., 2014; Kassah et al., 2013). According to Kiani (2009), one of the main challenges that all participants in two focus group discussions held in Cameroon shared was finding a suitable marital relationship. One woman stated that many men were afraid of women with disabilities due to the false belief that disability is contagious. Other women felt that African cultural norms expect women to perform household chores while bringing in an income. This places difficult expectations on women with disabilities, who are seen by men as 'unfit' partners (Kiani, 2009).

Besides obtaining a relationship, retaining a relationship it is also a problem for women with disabilities. The reviewed articles indicate a high divorce rate among women with disabilities who were married. If they manage to get married and become pregnant, their pregnancy may become a source of embarrassment. Many women with disabilities become embarrassed and this often prevents them from telling their in-laws about their pregnancy (Morrison et al., 2014). If they do not get married, women with disabilities are afraid of bringing shame on their family if their pregnancy is visible (Morrison et al., 2014). Emmet and Alant (2007) report in their study that women with disabilities are twice as prone to divorce or separation than women without disabilities. Both Braathen and Kvam (2008) and Kassah et al. (2013) found that the majority of women with disabilities in their study were divorced, widowed, or had never been married.

Braathen and Kvam (2008) mention pregnancy as one of the reasons for divorce among women with disabilities, as many men approach women with disabilities with the intention of exploiting them and using them as sex tools, rather than marrying them and having children. This is in accordance with the findings of Parnes et al. (2009), who studied the issues and implications of disability in low-income countries. A survey that they performed in Orissa, India, found that $100 \%$ of women and girls with disabilities were physically abused at home, $25 \%$ of women with intellectual disabilities had been raped, and $6 \%$ of women with disabilities had been forcibly sterilized.

If they succeeded in obtaining and retaining intimacy and married life, become pregnant and experienced motherhood, women with disabilities also experience many other problems. Regarding motherhood, women with disabilities, especially those with cognitive disabilities, have been stereotyped as incapable mothers (Gupta, 2013). Women with disabilities are discriminated against in relation to motherhood because of societal denial of maternity, parenting, and parental rights (Frohmader \& Ortoleva, 2013; Gupta, 2013). Accordingly, systemic prejudice and discrimination against them continues to result in multiple and extreme violations of their sexual and reproductive rights, through practices such as forced contraception and/or limited or no contraceptive choices, poorly-managed pregnancy and birth, forced or coerced abortion, the termination of parental rights, and denial of, or forced, marriage (Frohmader \& Ortoleva, 2013). The same authors state that the denial of the parental rights of women with disabilities can lead to the removal of their children as:

Recent data demonstrates that a parent with a disability (usually a mother) is up to ten times more likely than other parents to have a child removed from their care, with the child being removed by authorities on the basis of the parents' disability, rather than any evidence of child neglect. (Frohmader \& Ortoleva, 2013, p. 6)

The inaccessibility of health care services also limits pregnant women with disabilities from giving birth by increasing the likelihood of miscarriage and even death. Some sources suggest that women with disabilities also experience denial of maternal health services (Smith, Murray, Yousafzai, \& Kasonka, 2004).

\section{Discussion}

From this review, we can conclude that women with disabilities in LMICs experience huge difficulties with respect to education, employment and motherhood. This concerns both obtaining and retaining the roles (of student, employee, mother), as well performing them. On a personal level, this means that many women with disabilities experience inequality as they are excluded from living the life they would like. Even if not all women with disabilities long for education, employment or motherhood, those who do are deprived of "the right to autonomy and self-determination, i.e., the right of everyone to make free and informed decisions and have full control over their body such as being married and have children-without any form of discrimination, stigma, coercion or violence" (Frohmader \& Ortoleva, 2013, p. 2). This right also includes the roles of being a student or employee (Brown, Emerson, Falk, \& Freedman, 1971). 
The three social roles of student, employee and mother are interrelated. For example, providing disabled women with better education opportunities potentially has a great impact on increasing their employability; some of the reviewed articles found lack of education to be a factor in the low employment level of women with disabilities in LMICs. Consequently, the potential that women with disabilities demonstrate in their education and employment can be proof of their capability to fulfil other social responsibilities, such as married life and motherhood. For example, societies in LMICs generally exclude women with disabilities from motherhood responsibilities, which is one of the most socially valued roles in LMICs, as it is believed that they cannot take care of their children. Meanwhile, showing society that women with disabilities can be educated and employed implies that they can also handle other social roles and responsibilities, such as married life and motherhood. Their limited participation in the labour force results in reduced power and influence in decision-making, both at home and in the community (Kiani, 2009). Moreover, the financial power that women with disabilities acquire from their employment can contribute to the safe growth of their children, especially in LMICs where women with disabilities do not receive any financial support from the government. This, in turn, may minimize the fears men have about marrying women with disabilities with regard to the cost of married life and raising children (Tefera \& Van Engen, 2016).

As expressed in most of the reviewed articles, lack of means is an important cause of the low participation of women with disabilities in social roles. Poverty alleviation is stated as an important strategy for minimizing discrimination (Eide \& Ingstad, 2011). The link between inequality and poverty can be explained by considering the fact that poor people in LMICs generally lack essential means (such as adequate food, shelter, education, and health care) and access to employment in LMICs is limited. When it comes to women with disabilities, in addition to the poverty that they face alongside other citizens, their gender and disability make it harder for them to compete for the available resources with members of society without disabilities. In other words, the government and society prefer to invest the scarce resources for the betterment of those without disabilities. In some of the reviewed articles, parents were reported to be hesitant to invest in the education of children with disabilities, seeing it as a bad investment, as they believe that children with disabilities do not have the ability to succeed at school and will remain dependent on them whether they send them to school or not. So, there is a lack of awareness among the relevant stakeholders (governments, educators, employers, and families) in relation to the potential of people with disabilities.

Both social role theory and capability approach can be framed as helpful in identifying and analysing the important roles (capabilities) of disabled women. Moreover, the capability approach, in stating that people with less resources are entitled to more means to achieve equal outcomes, can serve as an intervention paradigm. The approach provides the theoretical base for a policy of 'positive discrimination'. This can also play a role in raising awareness of the issues faced by women with disabilities among stakeholders.

Lack of awareness can also give space to cultural beliefs that spark discrimination. For instance, in some communities, disability is considered to be a curse and families of children with disabilities are blamed for the presence of a disabled member, inferring that someone must have sinned and offended God. This moral model of disability takes disability as a defect caused by moral lapse, sin, or failure of faith (Olkin, 2002). Such beliefs may force families to hide their daughters with disabilities. Hence, the need for awareness creation arises (WHO \& World Bank, 2011). Economic empowerment and poverty alleviation alone cannot create a conducive environment for women with disabilities, without also convincing society that women with disabilities have the potential to learn, work and marry. These findings resonate with the concept of intersectionality, which conceives inequality as simultaneously caused by multiple and interactive factors such as gender, class, ethnicity and disability (Björnsdottir, 2010; Meekosha, 2011; Weber, 2001).

The valued roles of student, employee and mother lose some of their significance when it comes to the situation of women with disabilities. For example, giving birth without being married is not socially acceptable and, therefore, being an unmarried mother is a devalued role in most LMICs. But, when it comes to women with disabilities, being an unmarried mother becomes a valued social role, as women with disabilities are not expected to get married.

In general, the studies conclude that participation in important social roles and the achievement of valuable life goals is hampered for women with disabilities due to limited accessibility, stigma and lack of support. Poverty exacerbates this situation, as does discrimination, which hinders women with disabilities from participating and succeeding in these major life domains.

\section{Limitations}

In this review, the focus on education, employment and motherhood in LMICs does not allow consideration of all the challenges and opportunities faced by women with disabilities. The review may have been more critical and comprehensive if it had involved other important themes, such as health (the availability and accessibility of health centres). Similarly, focusing on LMICs in the search procedure limited the number of articles reviewed, as most of the literature available on these themes is written about developed countries. However, our focus did allow us to unfold issues on accessibility, stigma and support, which are important and intertwined moderators for individuals in achieving their capabilities in education, employment and family life. 


\section{Recommendation for Future Research}

Although the capability approach is a very useful framework guiding our review of the literature, the capability approach in principle suggests that what are essential and valued goals in life can only be articulated by people themselves (i.e., women with disabilities) and cannot be defined by policy makers, politicians or academics. We, therefore, call for research that uses approaches that give room for women with disabilities to articulate their valued goals in life and the opportunities and challenges that affect the accomplishment of these valued goals.

\section{Conclusion}

The review examined the important challenges and opportunities of women with disabilities in LMICs in relation to their participation in education, employment and motherhood, and the elements that regulate their participation in these important social roles. The theoretical frameworks, SRV and capability approach, helped us to systematically identify and precisely defined relationships among the three social roles of student, employee and mother.

The review found that there is a need to increase awareness and understanding among governments, educators, employers, and families about the life experiences of disabled women in LMICS. If different parts of society are aware and understand the need to fulfil the valued social roles and capabilities of disabled women in relation to education, employment, and motherhood, society will increase the inclusion of women with disabilities by sharing the available resources for the betterment of all citizens. Hence, it is important to develop a better understanding of the lives of disabled women in LMICs in order to minimize the obstacles to equality that they face in participating and succeeding in all valued social roles.

Moreover, governments, educators, employers and families need to understand that denying women with disabilities access to valued social roles deprives them of their basic human rights. CRPD states the need to respect differences and accept disabilities as part of human diversity and humanity, and emphasizes the need for equality and equality of opportunity between persons with disabilities and those without (United Nations, 2006). Furthermore, CRPD clearly requires state parties to ensure that persons with disabilities enjoy legal capacity on an equal basis with others (Frohmader \& Ortoleva, 2013).

Our final conclusion from the findings of the review is that there is a need to build a disability component into all aspects of national and international development efforts (Morrison et al., 2014). As presented by Groce et al. (2011) and Frohmader and Ortoleva (2013), the inclusion of persons with disabilities should be a routine part of all programmes that address chronic poverty, because the inclusion of disability in addressing poverty leads to the equal distribution of available resources, which minimizes discrimination against women with disabilities in LMICs in terms of participating and succeeding social roles in education, employment, and motherhood. Moreover, as some of the reviewed articles state, the authorities in LMICs should ensure justice by updating (and implementing) policies designed to minimize and prevent discrimination against disabled women. Furthermore, equal distribution of resources would allow disabled women to develop to their full potential in such a way that they can participate in all domains of life and contribute to their communities and society as a whole.

\section{Acknowledgments}

We take this opportunity to express our gratitude to the people who have been instrumental in the successful completion of this article. We would like to show our greatest appreciation to the Tilburg University librarian, Trijnie Horlings who assisted us in consulting the databases and Dr. Abeba Beyene who supported us in selecting the relevant articles based on the titles. We would like to thank NUFFIC, NICHE/ETH/020, for giving the scholarship grant to Belaynesh Tefera to attend the $\mathrm{PhD}$ program in Tilburg University and funding the field work expenses. We would also extend our gratitude for the support of the Institution School of Commerce, Faculty of Business and Economics, Addis Ababa University.

\section{Conflict of Interests}

The authors declare no conflict of interests.

\section{References}

Alkire, S. (2002). Dimensions of human development. World development, 30(2), 181-205.

Alkire, S. (2005). Why the capability approach? Journal of Human Development, 6, 115-133.

Björnsdottir, K. (2010). Resisting the reflection: Identity in inclusive life history research. Disability Studies Quarterly, 30(3/4).

Braathen, S. H., \& Kvam, M. H. (2008). Can anything good come out of this mouth? Female experiences of disability in Malawi. Disability and Society, 23(5), 461-474.

Brown, B. A., Emerson, T. I., Falk, G., \& Freedman, A. E. (1971). The equal rights amendment: A constitutional basis for equal rights for women. The Yale Law Journal, 80(5), 871-985.

Dark and Light Blind Care. (2008). Inclusion of disabled people in vocational training and income. An overview of international experiences and approaches. Light for the World, 1-37.

Dhungana, B. M. (2007). The lives of disabled women in Nepal: Vulnerability without support. Disability and Society, 21(2), 133-146.

Eide, A. H., \& Ingstad B. (2011). Disability and poverty: A global challenge. Bristol: Policy Press.

Emmett, T., \& Alant, E. (2006). Women and disability: Ex- 
ploring the interface of multiple disadvantage. Development Southern Africa, 23(4), 445-460.

Flynn, R., \& Aubury, T. (1999). Integration of persons with developmental or psychiatric disabilities: Conceptualization and measurement. In R. Flynn \& R. Lemay (Eds.), A quarter-century of normalization and social role valorization: Evolution and impact (pp. 271-304). Ottawa: University of Ottawa Press.

Frohmader, C., \& Ortoleva, S. (2013). The sexual and reproductive rights of women and girls with disabilities. Paper presented at the ICPD BEYOND 2014. International Conference on Human Rights, Australia.

Gardner, J., \& Carran, D. (2005). Attainment of personal outcomes by people with developmental disabilities. Mental Retardation, 43(3), 157-174. Groce, N., Kett, M., Lang, R., \& Trani, J.-F. (2011). Disability and poverty: The need for a more nuanced understanding of implications for development policy and practice. Third World Quarterly, 32(8), 1493-1513.

Gupta, R. (2013). Twin tracking for women with disabilities in disability legislation. Centre for Disability Studies, 1-21.

Hannula, L., Kaunoen, M., \& Tarkka, M.-T. (2007). A systematic review of professional support interventions for breastfeeding. Journal of Clinical Nursing, 17, 1132-1143.

Kassah, B. L. L., Kassah, A. K., \& Agbota, T. K. (2013). Abuse of physically disabled women in Ghana: Its emotional consequences and coping strategies. Disability and Rehabilitation, 36(8), 665-671.

Kiani, S. (2009). Women with disabilities in the North West Province of Cameroon: Resilient and deserving of greater attention. Disability and Society, 24(4), 517-531.

Kvam, M. H., \& Braathen, S. H. (2008). “I thought...maybe this is my chance". Sexual abuse against girls and women with disabilities in Malawi. Sexual Abuse, 20(1), 5-24.

Lamichhane, K. (2012a). Disability and barriers to education: Evidence from Nepal. Scandinavian Journal of Disability Research, 15(4), 311-324.

Lamichhane, K. (2012b). Employment situation and life changes for people with disabilities: Evidence from Nepal. Disability and Society, 27(4), 471-485.

Lemay, R. (2006). Social role valorization insights into the social integration conundrum. Mental Retardation, 44(1), 1-12.

Loeb, M., \& Eide, A. H. (2008). Poverty and disability in Eastern and Western Cape Provinces, South Africa. Disability and Society, 23(4), 311-321.

Meekosha, H. (2011). Decolonising disability: Thinking and acting globally. Disability \& Society, 26(6), 667-682.

Mitra, S., Posarac, A., \& Vick, B. (2011). Disability and poverty in developing countries: A snapshot from the World Health Survey (World Bank, SP Discussion Paper No. 1109).

Moodley, J., \& Graham, L. (2015). The importance of intersectionality in disability and gender studies.
Agenda, 29(2), 24-33.

Morrison, J., Basnet, M., Budhathoki, B., Adhikari, D., Tumbahangphe, K., Manandhar, D., . . . Groce, N. (2014). Disabled women's maternal and newborn health care in rural Nepal: A qualitative study. Midwifery, 30, 1132-1139.

Naami, A. (2015). Disability, gender, and employment relationship in Africa: The case of Ghana. African Journal of Disability, 4(1), 95-105.

Naami, A., Hayashi, R., \& Liese, H. (2012). The unemployment of women with physical disabilities in Ghana: Issues and recommendations. Disability and Society, 27(2), 191-204.

Nussbaum, M. (2006). Frontiers of justice: Disability, nationality, species membership. London: The Belknap Press of Harvard University Press.

OHCHR. (2012). Thematic study on the issue of violence against women and girls and disability. Geneva: $\mathrm{OHCHR}$.

Olkin, R. (2002). Could you hold the door for me? Including disability in diversity. Cultural Diversity and Ethnic Minority Psychology, 8(2), 130.

Opini, B. M. (2010). A review of the participation of disabled persons in the labour force: The Kenyan context. Disability and Society, 25(3), 271-287.

Ortoleva, S. (2010). Women with disabilities: The forgotten peace builders. Blue Law International, 33(83), 83-141.

Osburn, J. (2006). An overview of social role valorization theory. The SRV Journal, 1(1), 4-13.

Parnes, P., Cameron, D., Christie, N., Cockburn, L., Hashemi, G., \& Yoshida, K. (2009). Disability in lowincome countries: Issues and implications. Disability and Rehabilitation, 31(14), 1170-1180.

Price, J. (2011). The seeds of a movement-disabled women and their struggle to organize. Toronto: Association For Women's Rights in Development.

Robeyns, I. (2005). The capability approach: A theoretical survey. Journal of Human Development, 93-114.

Salome, N., Mbugua, P., \& Ong'eta, W. (2013). Gender and disability: Voices of female students with disabilities on gender based violence in higher education, Kenya. International Journal of Education and Research, 1(4), 1-12.

Saunders, M. N., \& Rojon, C. (2011). On the attributes of a critical literature review. Coaching: An International Journal of Theory, Research and Practice, 4(2), 156-162.

Sen, A. (1980). Description as choice. Oxford Economic Papers, 32(3), 353-369.

Sen, A. K. (1983). Poor, relatively speaking. Oxford Economic Papers, 35(2), 153-169.

Sen, A. K. (1992). Inequality reexamined. New York: Russell Sage Foundation.

Sen, A. K. (1993). Capability and well-being. In The quality of life.

Sen, A. K. (1999). Development as freedom. New York: Knopf. 
Sen, A. K. (2009). The idea of justice. Allen Lane: London. Simkhada, P. P., Shyangdan, D., Van Teljlingen, E. R., Kadel, S., Stephen, J., \& Gurung, T. (2013). Women's knowledge of and attitude towards disability in rural Nepal. Disability and Rehabilitation, 35(7), 603-613.

Smith, E., Murray, S. F., Yousafzai, A. K., \& Kasonka, L. (2004). Barriers to accessing safe motherhood and reproductive health services: The situation of women with disabilities in Lusaka, Zambia. Disability and Rehabilitation, 26(2), 121-127.

Tefera, B., \& Van Engen, M. (2016). The disability paradox: Better opportunities versus the hardships of high-achieving disabled women of Ethiopia. Canadian Journal of Disability Studies, 5(1), 107-132.

Tefera, B., Van Engen, M., Van der Klink, J., \& Schippers, A. (2017). The grace of motherhood: Disabled women contending with societal denial of intimacy, pregnancy, and motherhood in Ethiopia. Disability \& Society, 1-24.

Tuomi, M. T., Lehtomäki, E., \& Matonya, M. (2015). As capable as other students: Tanzanian women with disabilities in higher education. International Journal of Disability, Development and Education, 62(2), 202-214.

UN General Assembly. (2012). Human Rights Council resolution on the rights of persons with disabilities: participation in political and public life (A/HRC/19/L.9/Rev.1). New York: United Nations.

UN, \& UNC. (2012). Discussion paper for the informal session. Conference of states parties to the convention on the rights of persons with disabilities. New York: United Nations.
United Nations. (2006). United Nations convention on the rights of persons with disabilities. United Nations.

United Nations (n.d). Sustainable Development Goals. 17 goals to transform our world. http://www.un. org/sustainabledevelopment/sustainable-develop ment-goals

Venkatapuram, S. (2011). Health justice: An argument from the capabilities approach. Cambridge: Polity Press.

Weber, L. (2001). Understanding race, class, gender, and sexuality: A conceptual framework. Boston: McGrawHill.

WHO, \& World Bank (2011). World report on disability. Geneva: World Health Organization.

Wolfensberger, W. (1983). Social role valorization: A proposed new term for the principle of normalization. Mental Retardation, 21(6), 234.

Wolfensberger, W., \& Thomas, S. (2005). Introductory social role valorization workshop training package. Syracuse, NY: Training Institute for Human Service Planning, Leadership and Change Agency, Syracuse University.

Wolfensberger, W., Thomas, S., \& Caruso, G. (1996). Some of the universal "good things of life" which the implementation of Social Role Valorization can be expected to make more accessible to devalued people. International Social Role Valorization Journal, 2(2), 12-14.

Wolfswinkel, J. F., Furtmueller, E., \& Wilderom, C. P. (2013). Using grounded theory as a method for rigorously reviewing literature. European Journal of Information Systems, 22(1), 45-55.

\section{About the Authors}

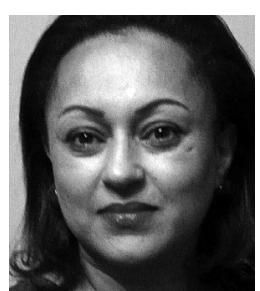

Belaynesh Tefera is a PhD candidate of Tilburg University, at the Department of Human Resource Studies, Faculty of Social and Behavioral Science. She is a lecturer in the marketing management department of School of Commerce, Faculty of Business and Economics, Addis Ababa University in Addis Ababa, Ethiopia. Her research interests are gender issues, inclusion of people (women and children) with disabilities, diversity in employment, any human resource related issues, motherhood, family life and social marketing.

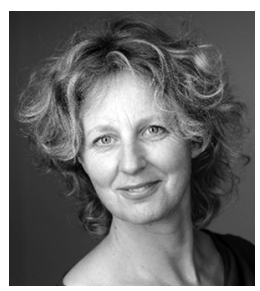

Marloes L. van Engen works at the Department of Human Resource Studies, Faculty of Social and Behavioral Sciences at Tilburg University where she lectures in Diversity in Organizations. She studied Social Psychology with a minor in the Psychology of Culture and Religion at the Radboud University in Nijmegen. Her research interests are in the area of gender at work, work-family issues in organizations, inequality in organizations, and (the management of) diversity and Inclusion in organizations. 


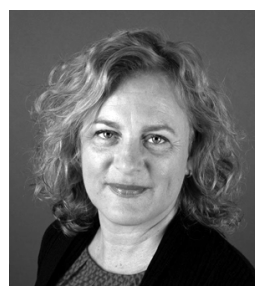

Alice Schippers (Msc, PhD), is a coordinating Senior Researcher at the Disability Studies unit of the Medical Humanities department of the VU University Medical Center in Amsterdam. She is also the General Director of Disability Studies in the Netherlands. She has worked for twenty years in policy, management, research and higher education in the disabilities field. Her research focus is on (family) quality of life, community building and inclusion and collaborative research. Alice is Vice President for Europe or IASSIDD and Chair of the International Special Interest Group on Quality of Life (IASSIDD).

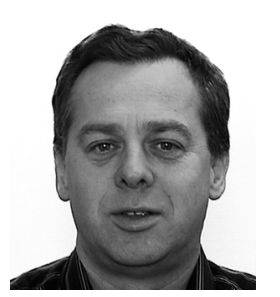

Arne H. Eide is Chief Scientist at SINTEF Technology and Society, Norway, Professor at the Norwegian University for Science and Technology, and Guest Professor at Stellenbosch University, South Africa. He has 20 years of experience in research on disability and poverty, community based rehabilitation and studies on living conditions in low-income countries, mostly in Africa, but also in the Middle East and in Asia. Eide has been engaged in Expert Committees on Disability statistics, Disability and Development and on Provision of assistive technology to low-income contexts by United Nations and World Health Organisation. He has published widely in the field of disability research and has contributed to the World Report on Disability as well as the 2012 EFA Global Monitoring Report.

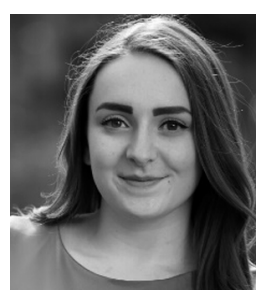

Amber Kersten is a bachelor student Human Resource Studies at the Faculty of Social and Behavioral Sciences, at Tilburg University. She follows a minor in Applied Social Psychology. Her interests lie in the field of data science and diversity \& inclusion policy, in which she is currently employed. In the future, she hopes to solve diversity-related issues, using data science, in order to create inclusion.

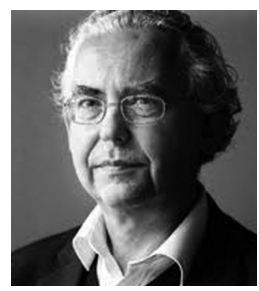

Jac van der Klink is since 2014 Full Professor of mental health at work and sustainable employability at Tilburg University, Tilburg School of Social and Behavioral Sciences, Tranzo (Centre for Care and Welfare). He studied Medicine and Psychology and he received postgraduate qualifications in general practice and occupational health. He worked as a physician in Ghana and as General Practitioner in the Netherlands. Subsequently, he worked among others in occupational health practice and as scientific director at the Netherlands School of Public and Occupational Health. From 2006 till 2014 he was Full Professor of occupational health at the University Medical Center in Groningen. His research focus is on mental health at work, on sustainable employability and on application of the capability model in these domains. Besides his academic affiliation he is (again) affiliated with the Netherlands School of Public and Occupational Health and with Ascender (a provider of psychosocial care for workers). 